Preference is given to letters commenting on contributions published recently in the JRSM. They should not exceed 300 words and should be typed double spaced
3 Lazarou J, Pomeranz BH, Corey PN. Incidence of adverse drug reactions in hospitalized patients. JAMA 1998;279:1200-5

\section{Animal experiments and the doctor}

Professor Vallance's editorial (June $2002 J R S M^{1}$ ) will be considered by most of your readers to be a well-balanced discussion on the use of animals in research. I too would agree with most of this article, were it not for the fact that I was trained as a veterinary surgeon who is acutely aware of the concept of species differences, not only between horses and canaries, but also between mice and men. However, most of my knowledge on the subject is the result of private research. I therefore believe that the reason 'the medical profession as a whole has remained rather quiet' is simply that most doctors have not made an in-depth study of the subject at hand. Most doctors do not know that the chimpanzees (our closest living relatives, with whom we share $98.4 \%$ of our DNA) are resistant to HIV, hepatitis B and common malaria. Similarly, most are not aware of the fact that humans are the only mammals who lack sialic acid on their cell surfaces, which represents a major obstacle to xenotransplantation (animal to human organ transplants), in addition to the other risks inherent in such transplants ${ }^{2}$.

The 3 Rs approach (replacement, reduction and refinement) is already out of date. This approach represents the old science of empiricism, based largely on experimentation and observation. The past 15-20 years have produced something of a scientific revolution, in terms of exact science. Is it really still necessary to perform toxic risk assessment on rodents and dogs, when we can observe the damaging effects of a chemical substance in human cell culture, at the molecular level?

The elucidation of the human genome clearly underlines the physiological differences between human individuals, let alone those between humans and animals. The way forward is individualized medicine, where patients will receive medication based on their genetic profile, thereby reducing the risk of adverse drug reactions which now rank as the fourth leading cause of death in western hospitals ${ }^{3}$. It should of course be noted that the medical drugs which are responsible for this virtual epidemic of adverse drug reactions were all thoroughly tested on laboratory animals, as is required by law. Does this sad statistic not say something about our regulatory system?

\section{Andre Menache}

President, Doctors and Lawyers for Responsible Medicine,

104 Weston Park, London N8 9PP, UK

\section{REFERENCES}

1 Vallance P. Animal experiments and the doctor. J R Soc Med 2002; 95:277

2 Gagneux P, Varki A. Genetic differences between humans and great apes. Molec Phylogenetics and Evolution 2001;18:2-13

\section{Management of testicular torsion}

Mr Pearce and his colleagues (May $2002 J R S M^{1}$ ) propose a protocol for management of suspected testicular torsion, based on their observations of clinical practice in the North West of England. They recommend fixation with delayedabsorption or non-absorbable sutures. There is, however, much controversy surrounding the method used for testicular fixation when a torted testis is deemed salvageable. Sutureless dartos muscle pouch fixation is a technique which is now increasingly being used by urologists and paediatric surgeons ${ }^{2}$. The main reason for this is that fixation with sutures, which traverse the blood-testis barrier, can generate an autoimmune response that leads to eventual infertility ${ }^{3}$. Suture fixation has additional complications. Non-absorbable sutures are associated with the formation of microabscesses and granulomas, predisposing to chronic testicular pain ${ }^{4}$, whilst absorbable sutures result in only fine adhesions at the site of placement and thus increase the risk of recurrent torsion ${ }^{5}$. Is suture fixation actually necessary? Eversion of the tunica vaginalis, as is performed in a Jaboulay procedure for hydrocele, leads to the formation of satisfactory adhesions and aids in the prevention of future torsion ${ }^{6}$. In conclusion, eversion of the tunica vaginalis together with sutureless fixation in a dartos pouch probably provides the best method of fixation.

\section{Iqbal Shergill}

\section{Manit Arya}

Institute of Urology and Nephrology, University College London, 67 Riding House Street, London W1W 7EY, UK

\section{REFERENCES}

1 Pearce I, Islam S, McIntyre IG, O'Flynn KJ. Suspected testicular torsion: a survey of clinical practice in North West England. J R Soc Med 2002; 95:247-9

2 Frank JD, O'Brien M. Fixation of the testis. Br J Urol Int 2002;89:331-3

3 Coughlin HT, Bellinger MF, La Porte RE, Lee PA. Testicular suture: a significant risk factor for infertility among formerly cryptorchid men. J Pediatr Surg 1998;33:1790-3

4 Morse TS, Hollabaugh RS. The 'window' orchidopexy for prevention of testicular torsion. J Pediatr Surg 1977;12:237-40

5 Sells H, Moretti KL, Burfield GD. Recurrent torsion after previous testicular fixation. Aust NZ J Surg 2002;72:46-8

6 Lent V, Stephani A. Eversion of the tunica vaginalis for prophylaxis of testicular torsion recurrences. J Urol 1993;150:1417-21

\section{Hugh Sinclair and the study of nutrition}

In her biography of Hugh Sinclair ${ }^{1}$, Jeanette Ewin refers to his letter entitled, 'Deficiency of fatty acids and atherosclerosis, etcetera' published in The Lancet in 1956. 
This communication cited evidence that, in rats, absence of particular chemical constituents of fats from the diet led to accumulation of cholesterol in blood vessels. Though controversial the letter stimulated new interest in possible associations between diet and health; it helped to extend the scope of nutritional studies beyond diseases such as beriberi, scurvy and rickets, associated with a deficient intake of particular vitamins or minerals.

Reviewing Ewin's book, Professor André McLean provides information of particular interest about Sinclair as a person (May $2002 J R S M^{2}$ ). Clearly, Sinclair was an eccentric, unable to find a comfortable niche within traditional academic departments; but there was another reason for his difficulties - namely, that the study of nutrition as a discipline then becoming apparent had its own philosophy and scope of inquiries which were not provided for in universities at that time. This was probably the true motivation for Sinclair's sad efforts during most of his academic life to establish an institute of human nutrition.

The science of nutrition must be based on the study of the anatomical, physiological, and pathological characteristics of individuals as these are influenced by the diet. These characteristics are determined not only by the diet but also by genetics, socioeconomic circumstances, exposure to infections and possibly other influences. No disease develops because of a single cause but because of interactions within a web of factors of which the diet may sometimes be one. Separate components of the web are not always present at the same time and one factor may permit or inhibit an effect of another at a future time.

The characteristics of an individual and their modification by diet, exposure to infections, bombardment of tissues by free radicals and other circumstances will influence the natural history of a disease. A clear understanding of this progression will require precise observations of numerous kinds, including frequent measurements of the amounts and kinds of food consumed. An institute of nutrition, as envisaged by Hugh Sinclair, might fulfil these requirements if it was dedicated to the study of cohorts of individuals, ideally from birth until death.

\section{George R Wadsworth}

Beech House, Barrule Park, Ramsey, Isle of Man IM8 2BR, UK

\section{REFERENCES}

1 Ewin J. Fine Wines and Fish Oil: The Life of Hugh Macdonald Sinclair. Oxford: Oxford University Press, 2001

2 McLean A. Book review. J R Soc Med 2002;95:263-4

\section{Cardiac intraventricular thrombus in protein $\mathbf{C}$ deficiency}

Mr Nair and his colleagues ${ }^{1}$ reported a patient with protein problems despite anticoagulant therapy. Three points for discussion arise. First, was the dose of warfarin sufficient, given the recurrent thromboses despite treatment? Although the APC ratio was normal, a case could be made for keeping the INR in such patients between 2.5 and 3.5, much as in patients with mechanical cardiac valve prostheses $^{2}$, despite the increased risk of haemorrhage. Second, might there be a second thrombophilia to account for the severe familial thrombotic tendency? Perhaps genotyping for the prothrombin gene mutation or other less frequently recognized thrombophilias should be performed in addition to the factor V Leiden genotyping ${ }^{3}$, as well as serology testing for cardiolipin antibodies. Finally, the value for plasma homocysteine $(88 \mu \mathrm{mol} / \mathrm{L})$ seems high despite the 'normal range' of 50-200: most laboratories quote a normal range for total plasma homocysteine between 5 and 15, depending on age and gender ${ }^{4}$.

\section{W M Hague}

Women's and Children's Hospital,

North Adelaide, South Australia 5006, Australia

\section{REFERENCES}

1 Nair KS, Weerasinghe A, Dahdal M, Gibbs JSR, Anderson JR. Cardiac intraventricular thrombus in protein $\mathrm{C}$ deficiency. $J \quad R$ Soc $M e d$ 2001;94:641-2

2 Litin SC, Gastineau DA. Current concepts in anticoagulant therapy. Mayo Clin Proc 1995;70:266-72

3 Kottke-Marchant K. Genetic polymorphisms associated with venous and arterial thrombosis - an overview. Arch Path Med 2002;126:295-304

4 de Bree A, Verschuren WMM, Blom HJ, de Graaf-Hess A, Trijbels FJM, Kromhout D. The homocysteine distribution: (mis)judging the burden. J Clin Epidemiol 2001;54:462-9

\section{Author's reply}

The patient was referred from the Middle East, where the target INR had been 2.0-3.0. Our own routine, in patients with prothrombotic conditions, is to maintain the INR between 2.5 and 3.5 - as in patients with mechanical valve prostheses. I fully agree with Dr Hague's suggestion of genotyping for the prothrombin gene and testing for cardiolipin antibodies in patients with recurrent arterial thrombosis. In our patient, normal prothrombin levels deterred us from performing genotype analysis, but we will follow up this patient on these lines. The homocysteine values were derived from an assay in which the normal range was as stated. It does vary considerably between different diagnostic kits world-wide.

\section{K S Nair}

Department of Transplant Immunology,

Heart Science Centre, Harefield Hospital,

Harefield, Middlesex UB9 6JH, UK 


\section{Domestic violence}

As one of the few men attending the RSM's conference on domestic violence with Dr Golding, I have no quarrel with his summary of what was presented by the speakers (June $2002 J R S M^{1}$ ). The point where I differ with what he has presented concerns the things that were not said but needed to be said at this meeting.

Anyone attending this conference fresh to the subject of domestic violence would have left with the belief that this age-old phenomenon was almost exclusively what men do to women and children. In the western world today, nothing could be further from the truth. There is a large body of work documenting violence in the domestic scene by women against men and children. In many studies the incidence is at, or close to, parity. The data come from the USA, Canada, New Zealand and Australia in addition to the UK. When this fact was raised from the floor during discussion, it was described as 'polarizing the argument' and the remarkable idea that 'women are only violent in response to violence from men'. Fortunately a keynote speaker, Dame Elizabeth Butler-Sloss, had referred to the unpalatable fact of female-perpetrated violence in the home. She also drew the conference's attention to the unmeasured volume of psychological abuse perpetrated by both sexes in the domestic environment, equally if not more damaging to the child.

Domestic violence deserves to be considered in a more balanced way at subsequent meetings on the subject.

\section{R J Walden}

Bossall, 126 Bluehouse Lane, Limpsfield, Surrey RH8 OAR, UK

\section{REFERENCE}

1 Golding AMB. Domestic violence. J R Soc Med 2002;95:307-8

\section{Immunotherapy for cancer}

Dr Grange and colleagues conclude that recent advances in the understanding of the nature of the immune response will enable a move 'from the empirical to the rational approach' in devising immunotherapy for cancer (June 2002 $\left.J R S M^{1}\right)$. They quote latent periods in the progress of cancer and of tuberculosis as evidence that an immune response is involved in both cases. This need not be so.

In both diseases there is cell death in the centre of masses (whether tubercles or cancers) that have outstripped their circulation ${ }^{2}$. In cancers the dead tissue may become organized and potentially proliferative cells sequestered, remote from blood-borne treatment and resistant to radiation through hypoxia. Successful treatment of the outer well-vascularized tumour leaves a core that may be slowly resorbed until the sequestered cells are exposed to a fresh blood supply; regrowth then occurs.
In the interpretation of so-called latent periods in cancer the most influential factor is a huge range of growth rates. In our series of unselected breast cancers ${ }^{3}$ the 95\% confidence intervals of the distribution of inferred volume doubling times were 6 and 121 days. Some 30 doublings of volume from a single cell are required to produce a clinically detectable tumour of about $1 \mathrm{~cm}$ in diameter. Thus growth from a single cell might take more than 10 years to achieve a diagnosable size. The published work abounds with much more slowly growing examples ${ }^{4}$. After treatments, any residual subclinical disease is unmeasurable over a range of sizes that represent three-quarters of the life-span of a tumour.

One may not assume that apparent delays in growth result from an immune response.

\section{Ann E Johnson}

Breast Study Centre, Mount Vernon Hospital, Northwood, HA6 2RN, UK E-mail: annjohnson@doctors.org.uk

\section{REFERENCES}

1 Grange JM, Stanford JL, Stanford CA. Campbell De Morgan's 'Observations on Cancer' and their relevance today. $J$ R Soc Med 2002;95:296-9

2 Thomlinson RH, Gray LH. The histological structure of some human lung cancers and the possible indications for radiotherapy. Br J Cancer 1955;9:539-49

3 Johnson AE, Bennett MH, Cheung CWD, Cox SJ, Sales JEL. The management of individual breast cancers. Breast 1995;4:100-11

4 Kusama S, Spratt JS, Donegan WL, Watson FR, Cunningham C. The gross rates of growth of human mammary carcinoma. Cancer 1972; 30:594-9

\section{Chronic subdural haematoma in the elderly}

In the series reported by Dr Asghar and colleagues (June $2002 J^{J S M^{1}}$ ) one-third of the subdural haematomas were in patients receiving antithrombotic therapy. It is a perverse paradox that thromboprophylaxis of age-related disorders such as atrial fibrillation and coronary thrombosis happens to be one of the most significant risk factors for subdural haematoma. Profiling of anticoagulant-related haemorrhagic risk might be of use in identifying those patients for whom alternative strategies, such as cardioversion to sinus rhythm (including drug treatment to prevent relapse), might be preferable for managing embolic risk in disorders such as atrial fibrillation. Profiling for CYP2C0 genetic variants shows promise, in this respect, with documentation of a significant association between warfarin-related haemorrhagic risk (including risk of life-threatening bleeding episodes) and either CYP2C9\#2 or CYP2C9\#3 polymorphism ${ }^{2}$, the hepatic microsomal enzyme CYP2C9 being the primary pathway for the metabolism of s-warfarin. For identification of risk of warfarin-related cerebral haemorrhage there is already evidence that there is an important 
role for profiling of the ApoE genotype, the latter being a marker for cerebral amyloid angiopathy ${ }^{3}$. In other words, through the use of genetic markers we might be able to identify who metabolizes warfarin abnormally or whose cerebral blood vessels are excessively friable, thereby facilitating the decision between antiarrhythmic therapy and warfarin.

\section{O M P Jolobe}

Department of Adult Medicine,

Tameside General Hospital,

Ashton-under-Lyne OL6 9RW, UK

\section{REFERENCES}

1 Asghar M, Adhiyaman V, Greenway MW, Bhowmick BK. Chronic subdural haematoma in the elderly - a North Wales experience. J R Soc Med 2002;95:290-2

2 Higashi MK, Veenstra DL, Kondo LM, et al. Association between CYP2C9 genetic variants and anticoagulant-related outcomes during warfarin therapy. JAMA 2002;287:1690-8

3 Rosand J, Hylek EM, O’Donnell HC, Greenberg SM. Warfarinassociated hemorrhage and cerebral amyloid angiopathy. Neurology 2000;55:947-51

\section{Dementia and ethics: views of informal carers}

The article by Dr Hughes and his colleagues (May 2002 $J R S M^{1}$ ) is excellent. May we briefly record our own findings. Between 1 September 2001 and 1 March 2002 we (DS) conducted interviews about all aspects of care with the marriage partners of 37 people with dementia attending our memory clinic. The group consisted of 28 women and 9 men, mean age 80 years (range 67-86), mean duration of marriage 40 years (26-58). All participants gave written informed consent. The study was approved by the Medical Ethics Committee of the Erasmus Medical Centre.

The ethical dilemmas described by Hughes et al. were reported by the partners in our study. In addition, we found that these older carers saw a duty to continue caring for their demented spouse despite the considerable physical and psychological stress of doing so. Two-thirds reported that they felt pressurized by their children, who considered it normal that they should carry out this task. Moreover, the partners reported that the children were often against the initiation of care which could ease the burden for the partner, such as that involving home help, district nurse, day care or day treatment. The children were perceived to be taking the side of the person with dementia, failing to recognize and support the efforts of the partner - a cause of additional psychological stress. We also observed that ethical dilemmas were more stressful and burdensome when the quality of the marriage was described as poor.

We were surprised to find that, despite intensive medical and psychosocial counselling from the early stages of dementia onwards, most partners felt that they had not been able to foresee the consequences of the dementia process and the associated tasks. Asking our social worker for help or telephoning him was considered a betrayal. The partners indicated that there were many moments when they hoped for a phone call or home visit from the social worker, which they themselves did not want to initiate because it made them feel guilty — as if they were doing it 'behind his back'. Feelings of guilt and betrayal arose especially in relation to decisions about stopping car-driving and about eventual placement in a psychogeriatric nursing home.

Our findings reinforce the message of Hughes and his colleagues - that professionals must be alert and sensitive to the ethical dilemmas faced by non-professional carers.

Tischa J M van der Cammen

\section{Daniël H Stuit}

Memory Clinic, Erasmus Medical Centre, Room D442, PO Box 2040, Rotterdam3000 CA, The Netherlands

\section{REFERENCE}

1 Hughes JC, Hope T, Reader S, Rice D. Dementia and ethics: the views of informal carers. J R Soc Med 2002;95:242-6 